\title{
A Novel Solution to Eliminate Frequency Intermittency by Adding Spinning Reserve to the Micro-Hydro Turbine Generator Using Real-Time Control of Induction Motor through AC-DC-AC Power Converters
}

\author{
Muhammad Farhan Masood*, Muhammad Irfan Abid**\$, Muhammad Shoaib Khalid***, Tasawar \\ Murtaza****, Muhammad Arshad Rasheed*****, Habib Ur Rehman******, Tausif Zahid*******, \\ * Department of Electrical Engineering, National University of Computer and Emerging Sciences, Islamabad, Pakistan. \\ **, $* * * * * * *$ Department of Electrical Engineering, Riphah International University, Islamabad. \\ *** Department of Electrical Engineering, National University of Computer and Emerging Sciences, Islamabad, Pakistan. \\ **** Department of Electrical Engineering, National University of Computer and Emerging Sciences, Islamabad, Pakistan. \\ ***** Department of Electrical Engineering, University of Engineering and Technology, Lahore, Pakistan. \\ ******Department of Electrical Engineering, Govt. College University Faisalabad, Pakistan.
}

(180854@nu.edu.pk, mirfanabid@riphahfsd.edu.pk, shoaib.khalid@nu.edu.pk, f180861@nu.edu.pk, arshadrustam786@gmail.com, engr.habib279@gmail.com, tausif.zahid@riphah.edu.pk )

$\$$ Corresponding Author; Muhammad Irfan Abid

mirfanabid@riphahfsd.edu.pk

Received: 11.10.2020 Accepted:09.12.2020

\begin{abstract}
Small micro-hydro has a variable output in terms of frequency and voltage. Formerly Electronic Load Controller (ELC) has been used to stabilize the output frequency of micro-hydro in which extra generated energy is wasted as heat. In this paper, a novel approach to handle these frequency variations by designing a Variable Frequency Drive (VFD) is proposed. Besides, the electronic governor of micro-hydro turbine generator is designed by incorporating a variable speed induction motor. Thus, the spinning reserve of the motor could be used for irrigation or water storage purposes by consuming extra generated power. Further, the DC bus of VFD enables the system to integrate with other Distributed Energy Sources (DES), which will be helpful in the future extension of the microgrid.
\end{abstract}

Keywords Micro Grid, Micro Hydro Power Plant (MHPP), Variable Frequency Drive, Frequency Stabilization.

\section{Introduction}

World's electricity demand is increasing day by day. Until 2035 there will be a $90 \%$ growth in world energy demand. However, $20 \%$ of the world's population still have no access to electricity [1]. This population is mostly settled in remote areas, where electricity transmission is a challenging task. These areas require a wide and costly transmission network for grid connectivity. So, in this situation, standalone power plants are preferably used to produce electricity. In these power plants locally available energy sources having the potential to produce electricity are used. In an area having the potential of multiple Renewable Energy Sources (RES) like Hydel, PV, Biomass etc. micro-hydro becomes a potential candidate of primary energy source. As it can provide 24 hours of energy at a lower cost [2]. In such type of stand-alone MHPPs, usually uncontrolled turbines are used because Governor Speed Control significantly increases the cost of the 
system [3]. Consequently, such micro-hydro plants have a variable output frequency because of water flow and consumer load variations

The rate of the water flow towards the turbine has a direct relation to turbine speed, when water flow increases, turbine speed will automatically increase. Consequently, the output power frequency will also increase. Conversely, as in the case of the lower water flow towards the turbine, the generated power frequency will decrease inevitably. To mitigate this problem mechanical control deployed towards the turbine side is used. In this control method, a mechanical valve is manually operated to control water flow. But it is an expensive solution for developing nations where they need to hire a person to operate valve according to the water flow. Furthermore, in this control method, the automatically operated valve could be used in a single pipe system or multi-pipe system with feedback [4]. These kinds of methods use an electrical controller to enhance performance. Multiple methods like Speed Droop Control (SDC) [5], Gate Limit Control (GLC) [6], Speed Level Control (SLC) [7] have been used to control turbine speed [8]. But these methods increase generation cost, need regular maintenance, and slows down the process.

If the consumer increases the load on the system, stress on the generator will also increase, and the generator will reduce its speed. As a result, the frequency of the generated power will be reduced. Conversely, if the load decreases, the generator speed will increase, and consequently, the frequency will also increase. Previously, this problem was resolved through the deployment of electrical controller known as Electronic Load Controller (ELC) towards the generator side. In this control technique, resistors are used to dump extra generated power [9]. This type of control as compared to mechanical control methods is economical, simpler, has a fastdynamic response, and is easy to maintain. Initially, rectifiers with chopper feeding resistors on the DC side were designed [10]. But such type of systems was capable to handle the resistive load only, they insert harmonics in the system, and distort the system voltages. Afterwards, IGBTs based controllers were introduced in which extra power was dumped in the form of heat using power converters [11]. These kinds of controllers are applied only on low power rating systems. However, for three-phase higher rating system, it's not a feasible option to dissipate such a huge amount of power. In addition to this frequency, variations were tackled by using multiple control valves and reducing dump load [12]. In these techniques, two-pipes, single valve control and three-pipes, two-valve control schemes were used [13]. These techniques waste power, although these were cost-effective. Afterwards, distributed electronic load controllers at the domestic level were used to utilize extra generated power for useful purposes by heating water in homes [14]. But these controllers also insert switching harmonics in the system and become the reason of thermal stresses. Subsequently, a modified electronic load controller was proposed which reduced the inserted harmonics in the system, but this controller also wastes power as heat [15]. In some studies, a VFD was used to integrate a micro-hydro power plant and a motor. In this system, the primary load was directly fed from micro-hydro and Field Oriented Control (FOC) [16] and Direct Torque Control (DTC) method [17] of the VFD by using micro-hydro frequency as a reference to control and operate the secondary load. Additionally, a microgrid was built where solar power plant extra generated power was used to pump water into the reservoir [18]. Later, a micro-hydropower plant with an energy storage system was proposed, but this solution is not economically viable [19]. This system requires too many batteries to store energy and need regular costly maintenance.

This paper proposes a Variable Frequency Drive (VFD) with an electronic governor to mitigate the problem of frequency fluctuations caused by both water flow variations and consumer load variations more effectively. VFD is a power converter which comprises of AC-DC-AC stages. These power conversion stages are used to convert the output power of micro-hydro having a variable frequency into a stable DC, then to a stable AC having a constant $50 \mathrm{~Hz}$ frequency, which is supplied to the load. Afterwards, a variable speed induction motor as an electronic governor is used in the replacement of ELC. This electronic governor connects with the DC bus of VFD using another DC-AC inverter. Where the spinning reserve could be used for irrigation or water storage purposes by consuming extra generated power.

This work comprises of 4 sections; Section 2 explains the Methodology of the proposed solution, Section 3 explains and discusses the Results of the system and Section 4 describes the conclusion of the system.

\section{Methodology}

The designed system comprises of a MHPP, Variable Frequency Drive power conversion stages (AC-DC, Filtration, DC-AC), primary load, secondary load (Variable speed Induction motor), and a controller to quantify extra power to dump. Fig. 1, shows the block diagram of the designed system.

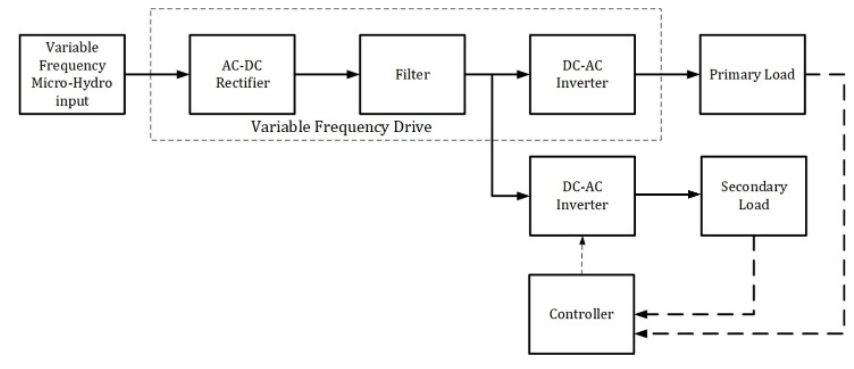

Fig. 1. Designed System Block Diagram.

Firstly, a basic model of micro-hydro is designed. Afterwards, a variable frequency drive is designed and integrated between the primary load and the micro-hydro. Subsequently, an electronic governor of micro-hydro is designed in which induction motor is used as governor and secondary load.

\subsection{Designing of Micro Hydro Power Plant}

Micro-Hydro as an electrical power source comprises of three main parts. 


\subsubsection{Hydraulic Turbine}

In a hydraulic turbine, the potential or kinetic energy of water is converted into mechanical energy which becomes the input of a generator.

Thus, the power is calculated by Eq. (1).

$$
P=Q * \rho * g * h
$$

In which

$\mathrm{g}$ is the gravitational coefficient acceleration

$\mathrm{h}$ is head height and is taken as $2 \mathrm{~m}$

$\mathrm{Q}$ is water discharge rate and is taken as $0.81634 \mathrm{~m} 3 \mathrm{~s}-1$

$\rho$ is the density of water and is taken as $1000 \mathrm{kgm}-3$

In this paper, a $16 \mathrm{kVA}$ system is designed by implementing the Eq. (1). As a hydraulic turbine, where water discharge rate $\mathrm{Q}$ is taken constant initially for model validation and later it is taken as a variable to produce variable mechanical power because of water flow variation towards the turbine.

\subsubsection{Excitation System}

This is the second main part of the micro-hydro which is used to provide the excitation and to regulate the terminal voltage of the synchronous machine in generating mode. This excitation system comprises two main components, voltage regulator and an exciter, which is designed by the implementation of the transfer function shown in Eq. (2).

$$
\frac{V_{e}}{V_{R}}=\frac{1}{\mathrm{~K}+\mathrm{sT}}
$$

Where

$\mathrm{V}_{\mathrm{e}}$ is the exciter voltage

$V_{R}$ is the regulators output

$\mathrm{K}$ is the exciter gain

$\mathrm{T}$ is the exciter time constant

Excitation is kept constant at $1 \mathrm{pu}$.

\subsubsection{Generator}

A generator is the third main part of the micro hydro electrical source design in which simplified synchronous machine is used as a generator, where every phase comprises of the voltage source in series with RL impedance. Eq. (3), shows the mathematical model of the implemented mechanical system.

$$
\Delta \omega(t)=\frac{1}{2 H} \int_{0}^{t}\left(T_{m}-T_{e}\right)-K_{d} \Delta \omega(t) d t
$$

Where

$$
\omega(t)=\Delta \omega(t)+\omega_{o}
$$

$\Delta \omega$ is a variation of speed analogous to the operation speed

$\mathrm{H}$ is the inertia constant

$\mathrm{T}_{\mathrm{m}}$ is the mechanical torque

$\mathrm{T}_{\mathrm{e}}$ is the electromagnetic torque

$\mathrm{K}_{\mathrm{d}}$ is a damping factor

$\omega(t)$ is the rotor mechanical speed

$\omega_{o}$ is the operation speed

Equation (4) shows the relation between mechanical power $\left(\mathrm{P}_{\mathrm{m}}\right)$ and power angle $(\delta)$ of internal voltage and the terminal voltage

$$
\frac{\delta}{P_{m}}=\frac{\omega_{s} / 2 H}{s^{2}+2 s \zeta \omega_{n}+\omega_{n}^{2}}
$$

where

$\zeta$ is the damping ratio

$\omega_{\mathrm{s}}$ is the electrical frequency

$\omega_{\mathrm{n}}$ is the electromechanical frequency

After designing the micro-hydro turbine-generator, mechanical power is kept $1 \mathrm{pu}$ and tested at full generating capacity $(16 \mathrm{kVA})$ and with a load equal to the total generating capacity $(16 \mathrm{kVA})$. Afterwards, it was tested at full generation capacity and the variable load from $7 \mathrm{kVA}$ to $17 \mathrm{kVA}$. After that, the testing of micro-hydro turbine-generator with variable input mechanical power is performed.

\subsection{Design and Integration of VFD}

A standard VFD, which is a power conversion device, comprises of three stages, as shown in Fig. 2. In this figure, $\mathrm{AC}$ to $\mathrm{DC}$ conversion, DC filtration, and $\mathrm{DC}$ to $\mathrm{AC}$ inversion are first, second, and third stages of power conversion respectively.

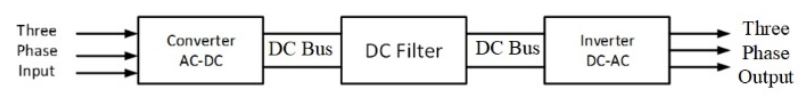

Fig. 2. Power Conversion Stages of Standard VFD.

In this system, all three stages of VFD are designed and implemented.

\subsubsection{AC-DC Conversion (Rectification)}

The signal having variable frequency is the input to the VFD. Firstly, rectification is performed in which power is converted from AC to DC. To convert AC to DC three-phase uncontrolled full-wave bridge rectifier is used where every diode conducts for $120^{\circ}\left(1 / 3^{\text {rd }}\right)$ in the supply cycle. At each instant, 2 diodes operate in a pair and every pair conduct for $60^{\circ}\left(1 / 6^{\text {th }}\right)$ of a cycle. Equation (5) - (7) are used for rectifier designing purposes.

$$
\begin{gathered}
V_{d c}=\frac{3 \sqrt{3}}{\pi} V_{s} \\
V_{s}=\frac{V_{L(\text { peak })}}{\sqrt{3}}
\end{gathered}
$$

where

$\left.\mathrm{V}_{(\mathrm{L}(\text { peak) }}\right)$ is the maximum line to line voltage

$$
V_{L(\text { peak })}=V_{L(R M S)} * \sqrt{2}
$$




\subsubsection{Filtration}

After converting into DC, the voltage has ripples because of variable frequency input. So, to remove these ripples capacitor bank on the DC bus is used. This capacitor bank is calculated by using Eq. (8) - (10). Calculations are done by keeping frequency $45 \mathrm{~Hz}$ to $70 \mathrm{~Hz}$. Afterwards, capacitor suitable to remove maximum ripples is used as a DC link capacitor.

$$
r=\frac{V_{r(p p)}}{V_{D C}}
$$

In which

$r$ is ripple factor

$V_{D C}$ is the dc value of the output voltage

$$
V_{D C}=\left(1-\frac{1}{2 f R_{l} C}\right) V_{p(r e c t)}
$$

$\mathrm{V}_{\mathrm{r}(\mathrm{pp})}$ is peak to peak ripple voltage at the output

$$
V_{r(p p)}=\frac{V_{p(r e c t)}}{f R_{l} C}
$$

$\mathrm{f}$ is the input frequency

$\mathrm{C}$ is a capacitor at the output to eliminate ripples $V_{p(\text { rect })}$ is the unfiltered peak full-wave rectified voltage.

\subsection{3. $D C-A C$ Inversion}

DC-AC Inversion is the third stage of the VFD in which power is converted from stable DC to a three-phase output signal. A three-phase voltage source inverter (VSI) controlled through the third-harmonic injection technique is used to achieve a stable output signal having $50 \mathrm{~Hz}$ constant frequency. Further Eq. (11) - (12) are used for inverters design and calculations.

$$
\begin{gathered}
V_{p}=\frac{V_{s}}{\sqrt{3}}=0.577 V_{s} \\
V_{L}=\sqrt{3 V_{p}}=\sqrt{3} * 0.577 V_{s}=V_{s}
\end{gathered}
$$

$\mathrm{V}_{\mathrm{p}}$ is the peak amplitude.

$\mathrm{V}_{\mathrm{L}}$ is the peak line voltage.

After designing VFD, it is integrated between MHPP and primary load. This VFD is different from conventional VFD. Conventionally available VFD have fix input frequency signal $50 \mathrm{~Hz} / 60 \mathrm{~Hz}$ but this newly designed VFD could take input of $45 \mathrm{~Hz}$ to $70 \mathrm{~Hz}$ and provide an output signal of $50 \mathrm{~Hz}$.

\subsection{Design of Electronic Governor of Micro-hydro turbine- generator}

A variable-speed induction motor is integrated as a governor in the system. This motor is considered as a secondary load and connected to the DC bus of VFD using a three-phase DC-AC inverter. This inverter is controlled to supply only extra generated power to the variable speed induction motor of $16 \mathrm{kVA}$, have the speed of $1460 \mathrm{RPM}$, nominal RMS voltage $400 \mathrm{~V}$ and $50 \mathrm{~Hz}$ frequency. This motor provides spinning reserve which could be used for irrigation or water storage purposes. Fig. 3 and Fig. 4 shows the designed controller diagram and how the electronic governor is integrated respectively.

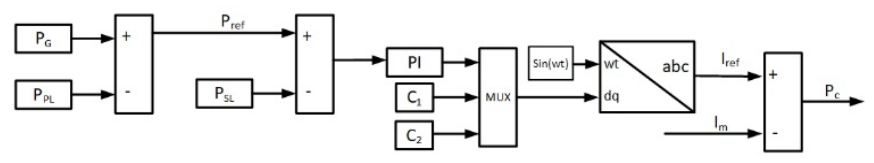

Fig. 3. Control methodology of Three Phase DC-AC Inverter for electronic governor.

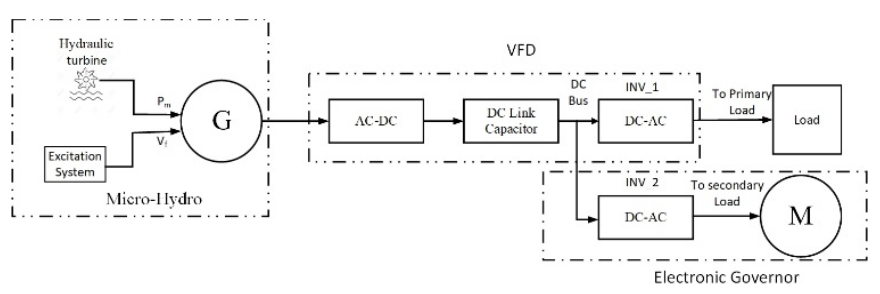

Fig. 4. Design of integrated Induction motor as electronic governor.

This controller maintains a power balance between maximum generation capacity of micro-hydro and load. This balance is maintained by operating the governor to use extra generated power. This dump power is calculated by taking the difference between the maximum generation capacity of $16 \mathrm{kVA}$ and operating load power, this calculated reference power controls the inverter to supply specifically calculated amount of power to the motor. By maintaining this balance micro-hydro always operate on its maximum capacity.

\section{Results and Discussion}

The designed system is validated and tested for five different scenarios. In the first scenario, micro-hydro is operating at its full constant capacity and constant load in which designed system shows operating at constant stable 50 $\mathrm{Hz}$ frequency. In the second scenario, generation is kept constant and the load is varied in which frequency of load varies with respect to the load variation. Afterwards, in the third scenario, mechanical input to the generator is varied by water flow variation and the system shows variable frequency due to variable water flow variation towards the turbine. In the fourth scenario designed variable frequency drive is integrated with the system in the result of that system having variable water flow and constant load behave as a stable system providing constant $50 \mathrm{~Hz}$ frequency. At the end designed electrical governor is validated in case of a system having both variable input water flow and the load.

\subsection{Testing of Micro-hydro Turbine-Generator for constant generation and load}

In this case, designed micro-hydro is tested for its full generation capacity (16 kVA) and at full RLC load (16 kVA). For this purpose, the mechanical power of $1 \mathrm{pu}$ by keeping 
water flow discharge rate constant is provided to the generator. It is evident in Fig. 5 that the system is generating and consuming $16 \mathrm{kVA}$ power. Same as Fig. 6 shows load current and its frequency. As ideally frequency of the uncontrolled micro hydro power plant gets stable after some time. Therefore, the designed micro-hydro is validated by showing $70 \mathrm{~Hz}$ frequency at the start but after some time become stable $50 \mathrm{~Hz}$. This frequency of the load current is constant $50 \mathrm{~Hz}$ because the system is operating at its full capacity.
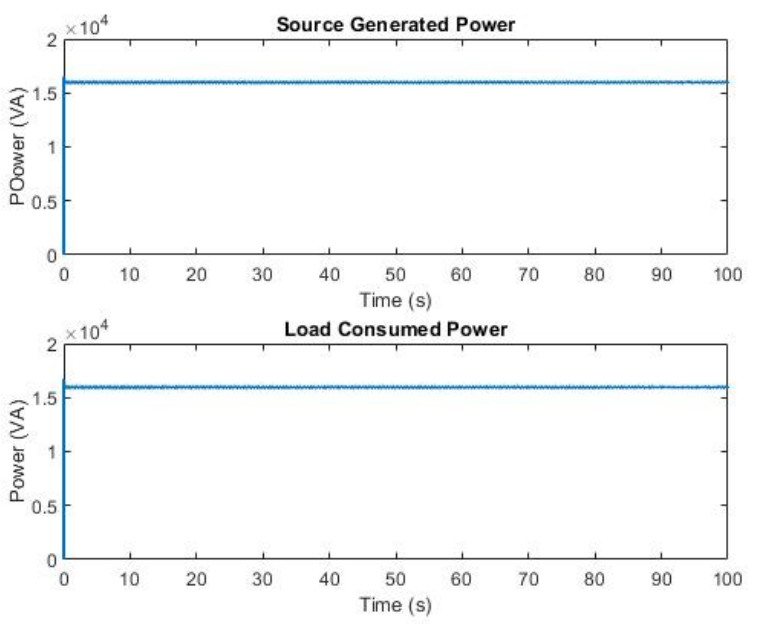

Fig. 5. (a) Micro-Hydro total Generated Power (b) Total Consumed Power.

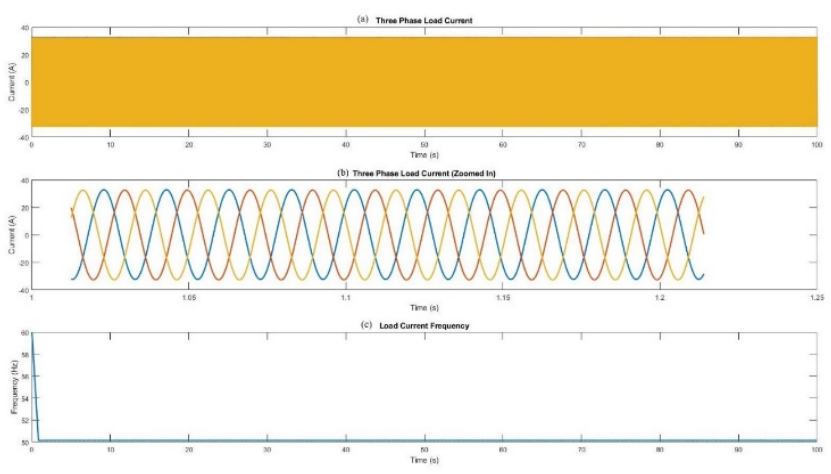

Fig. 6. (a) Three-phase Load Current, (b) Current Zoomedin View (c) Load Current Frequency.

\subsection{Testing of Micro-hydro Turbine-Generator for constant generation and variable load}

In this case, the same source of $16 \mathrm{kVA}$ by considering the constant input mechanical power of $1 \mathrm{pu}$ is used and load on the system is varied. The load is varied from a minimum of $7 \mathrm{kVA}$ to the maximum $17 \mathrm{kVA}$. So, the frequency of the load current variates with respect to load variation. Initially, the load on the system is kept to $7 \mathrm{kVA}$ after 20 seconds this load is increased to $11 \mathrm{kVA}$ then at the time of 40 -second load is again increased to $16 \mathrm{kVA}$ afterwards load is varied to $17 \mathrm{kVA}$ at the $50 \mathrm{~s}$ which is the maximum load tested on the system. Furthermore, after testing at $17 \mathrm{kVA}$ load is decreased to $12 \mathrm{kVA}, 11 \mathrm{kVA}, 7 \mathrm{kVA}$, on the 70 s, 75 s and 80 s, respectively. It is evident from Fig. 7 the load current variation concerning the time in the $20 \mathrm{~s}, 40 \mathrm{~s}$, $50 \mathrm{~s}, 70 \mathrm{~s}, 75 \mathrm{~s}$, and $80 \mathrm{~s}$ sequence, zoomed-in load current which shows the system has sinusoidal waveform, and the change in frequency with respect to the load variation. This case shows systems current frequency varies when we have constant mechanical power and variable load. It shows when the load is less than the total generating capacity $(16 \mathrm{kVA})$ the load current frequency is increased when the load is equal to total generating capacity ( $16 \mathrm{kVA}$ ) load current frequency becomes constant 50 $\mathrm{Hz}$ and when the load is greater than the total generating capacity (16 kVA) load current frequency is decreased with respect to change in load.

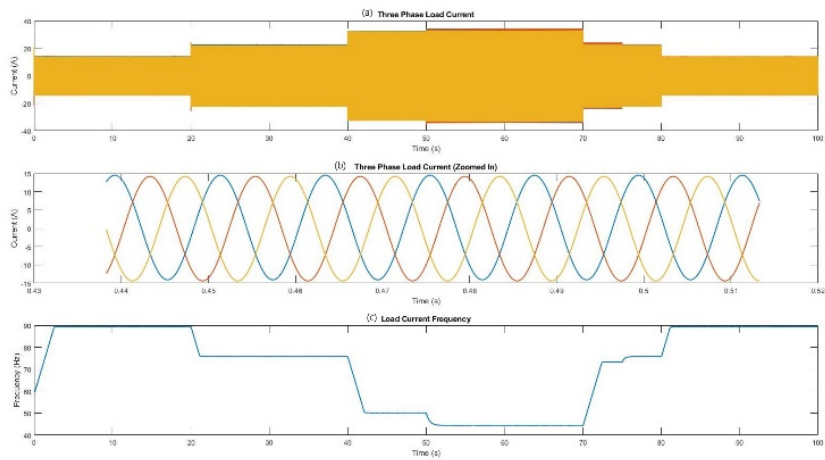

Fig. 7. (a) Three-phase Load Current, (b) Current Zoomedin View (c) Load Current Frequency.

\subsection{Testing of Micro-hydro Turbine-Generator with variable input water flow}

Micro-hydro turbine-generator with variable mechanical input power is tested. To produce variable mechanical input power towards the generator, the rate of water flow (Q) towards the turbine is made variable with respect to time and the fixed RLC load of $16 \mathrm{kVA}$ is used. Fig. 8 shows three-phase load current, zoomed-in load current which shows the system is stable and have stable sinusoidal waveform, and the timevariant frequency $(45 \mathrm{~Hz}-70 \mathrm{~Hz})$ of load current. This load current frequency variation is only due to water flow variation towards the turbine.

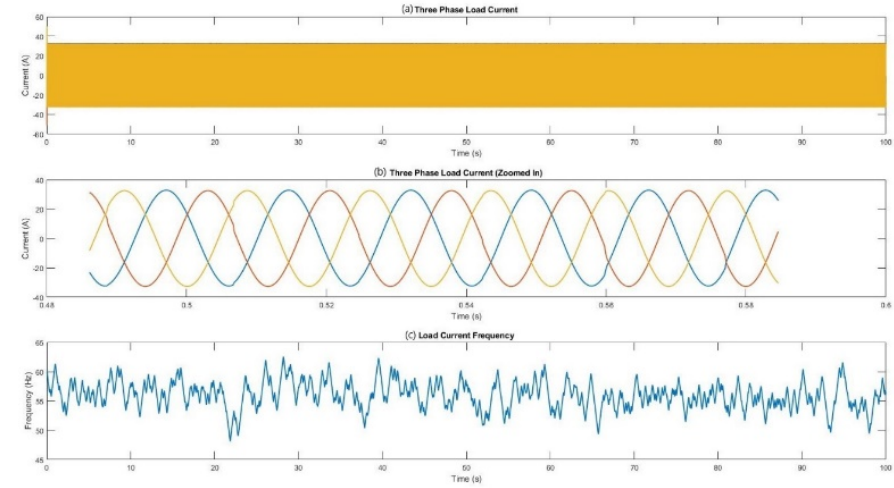

Fig. 8. (a) Three-phase Load Current, (b) Current Zoomedin View (c) Load Current Variable Frequency. 
These three scenarios validate designed micro-hydro turbine generator model by showing that in the absence of the governor, micro-hydro has a variable output frequency because of load variation and change in the rate of the water flow towards the turbine.

\subsection{System Validation after Integrating Designed VFD}

Afterwards, the system is tested after integrating designed Variable Frequency Drive between the designed uncontrolled micro-hydro and the load. Here the system tested under case 3.3 conditions is considered. Fig. 9 shows that the load current towards the load side has a constant $50 \mathrm{~Hz}$ frequency, however, input frequency is varying from $45 \mathrm{~Hz}$ to $70 \mathrm{~Hz}$. This result validates designed VFD is functioning as per desire and mitigate variable frequency issue due to variable water flow towards the turbine.
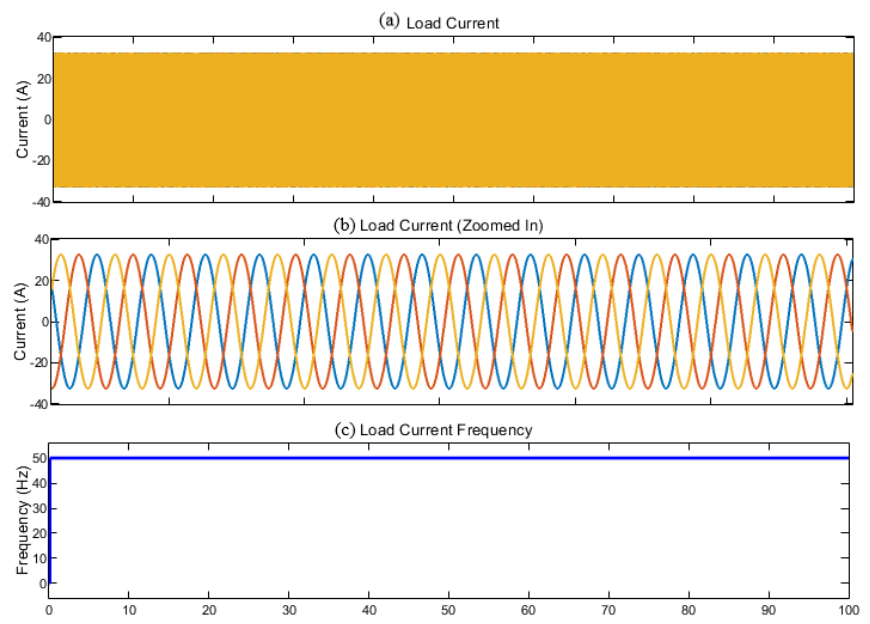

Fig. 9. Load Current, (b) Zoomed in Load Current (c) Load Current Frequency.

\subsection{System Validation after Integrating Designed Electronic Governor}

Then, a Variable Speed Induction motor is incorporated as governor using another DC to AC inverter connected with the DC bus of the VFD. The main load which is labelled as the primary load is of $16 \mathrm{kVA}$ and motor labelled as the secondary load is also of $16 \mathrm{kVA}$. Fig. 10 shows the power consumed by the Primary and Secondary load. As per system total generated power is $16 \mathrm{kVA}$. When consumer load power is less than $16 \mathrm{kVA}$ dumped power, which is delivered to the secondary load is increased. Initially, the load is at a maximum of $16 \mathrm{kVA}$, so the secondary load power consumption is zero. Then at 10 seconds, primary load decreases to $13 \mathrm{kVA}$ so the secondary load start consuming $3 \mathrm{kVA}$ power, so at 30 seconds primary load is more decreased to $11 \mathrm{kVA}$ so the secondary load power consumption increases to $5 \mathrm{kVA}$. In general, during time interval $0-50$ s consumer load power decreases from $16 \mathrm{kVA}$ to $8 \mathrm{kVA}$, inversely dumped power increases from 0 to $8 \mathrm{kVA}$. Same as, in the time interval 60 100 s consumer load power increases from $8 \mathrm{kVA}$ to $16 \mathrm{kVA}$, inversely dumped power decreases from $8 \mathrm{kVA}$ to $0 \mathrm{kVA}$.

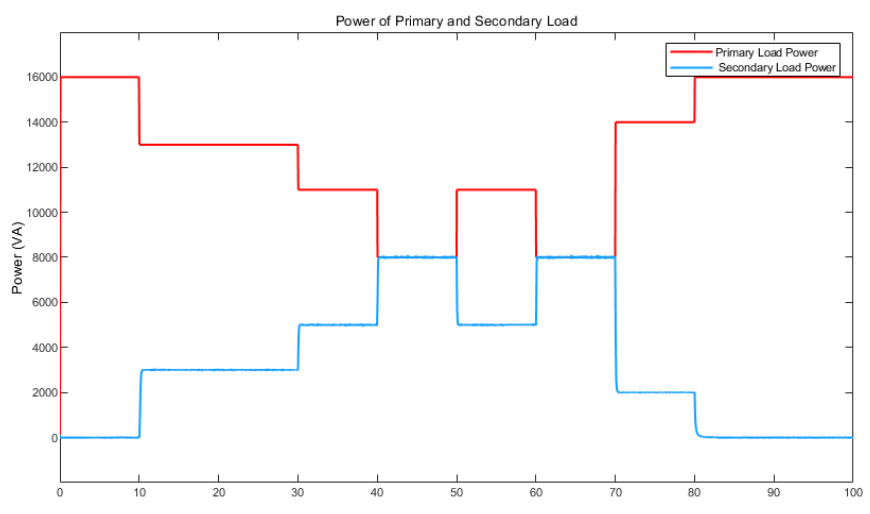

Fig. 10. Power Consumed by Primary and Secondary Load.

Fig. 11 shows primary and secondary load currents variation in different time intervals due to the main load variation. In time interval 0-50s consumer load current decreases due to a decrease in load from $16 \mathrm{kVA}$ to $8 \mathrm{kVA}$, inversely dumped load current increases due to power increases from 0 to $8 \mathrm{kVA}$. Same as, in the time interval $60-100$ s primary load current increases due to consumer load power increases from $8 \mathrm{kVA}$ to $16 \mathrm{kVA}$, inversely dumped load current decreases due power decreases from $8 \mathrm{kVA}$ to $0 \mathrm{kVA}$.

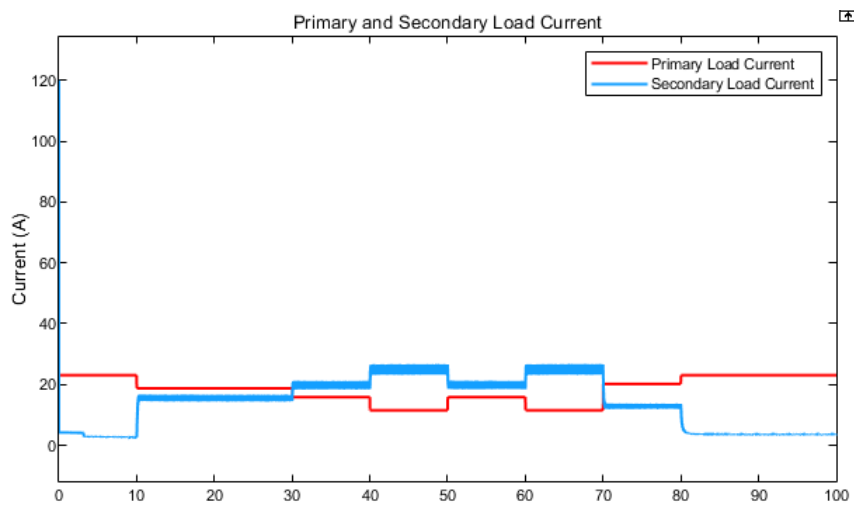

Fig. 11. Primary and Secondary Load Currents Variation in Different Time Intervals by Varying Main Load.

Fig. 12 shows primary/main Load Current, zoomed-in main load current and the frequency of the main load current. This case proves that in the case of consumer load variation the load current supplied to the primary load has a constant $50 \mathrm{~Hz}$ frequency because of the designed electric governor.

These results are validating that the load current supplied to the primary load has a constant $50 \mathrm{~Hz}$ frequency because of the newly designed electronic governor. Fig. 12 shows consumer load current varies at time $10 \mathrm{~s}, 30 \mathrm{~s}, 40 \mathrm{~s}, 50 \mathrm{~s}, 60 \mathrm{~s}$, $70 \mathrm{~s}$, and $80 \mathrm{~s}$, but it has a constant frequency of $50 \mathrm{~Hz}$. Results validate the designed governor. It shows that micro-hydro is constantly generating power at its full generation capacity, the governor is maintaining the power balance between microhydro and load by dumping the power which is not absorbed by the primary load, and the motor is consuming the only specific extra calculated amount of power. Consequently, the power supplied to the primary load has a constant desirable frequency which reduces the vulnerability of the system and makes the system capable to synchronize with other AC sources. 

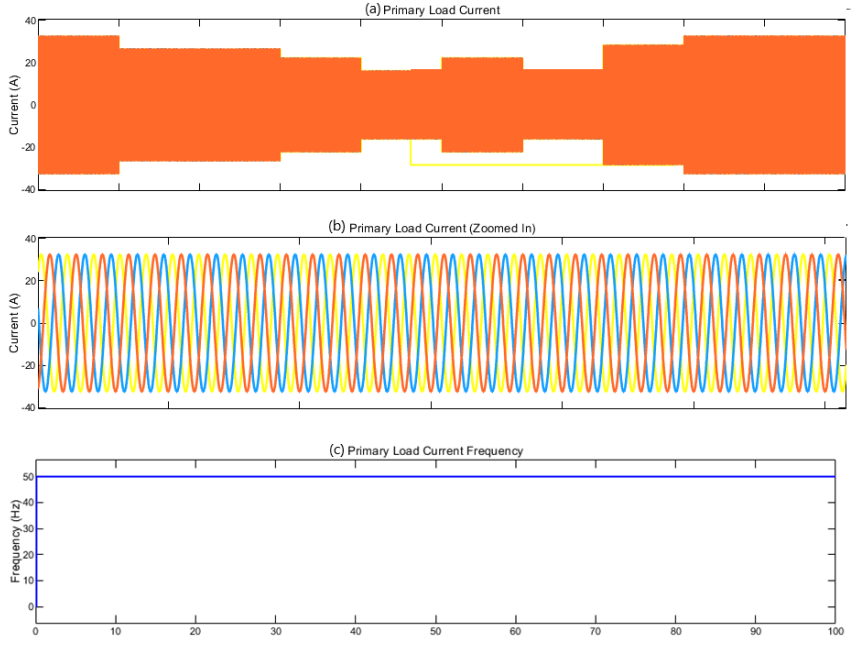

Fig. 12. (a) Primary/Main Load Current, (b) Zoomed in Main Load Current (c) Main Load Current Frequency.

This system is significant as compared to previously proposed systems. As most of the previously proposed systems were tested on resistive load only but this system is tested on RLC load. Furthermore, previously proposed ELC based systems deals with only over frequency cases. However, this system deals with under frequency impacts as well. As results show stable $50 \mathrm{~Hz}$ frequency of primary load in case of $45 \mathrm{~Hz}$ input. Moreover, in previous ELC based systems under frequency due to lower water flow toward the turbine was neglected. But in this system frequency variations due to water flow towards the turbine are also considered.

\section{Conclusion}

In this work, micro-hydro turbine-generator model is designed. The model is tested and validated for a constant full capacity generation, constant load, variable load, and variable input water flow rate. Afterwards, a VFD is designed and incorporated between load and micro-hydro. This VFD mitigates variable frequency impacts on load by providing a constant $50 \mathrm{~Hz}$ frequency signal to the load except having variable input frequency $45 \mathrm{~Hz}$ to $70 \mathrm{~Hz}$. Furthermore, the electronic governor of micro-hydro turbine-generator is designed, in which variable speed induction motor of $16 \mathrm{kVA}$ is integrated as governor. This motor is attached to the DC bus of the VFD through an inverter and consumes extra generated power of the source. This spinning reserve by the motor could be used for useful purposes like to fill water in a storage tank or for irrigation purposes. In addition to this, in future, the DC bus of the VFD could be used to integrate more renewable energy sources like PV or fuel cell with the existing system. So, this system could prove helpful in mitigating Renewable Energy Sources integration problems.

\section{References}

[1] Greening energy - OECD", Oecd.org, 2019. [Online]. Available: http://www.oecd.org/greengrowth/greeningenergy/. [Accessed: 17- Sep- 2019].
[2] M. I. Abid, M. S. Khalid, M. Kamran, M. A. Rasheed, M. F. Masood, and T. Murtaza. "Design and Optimization of the Micro-Hydro Power System for Remote Areas of Pakistan." International Journal of Smart Grid-ijSmartGrid 4, no. 3 (2020): 125-138.

[3] H. Iman-Eini, D. Frey, S. Bacha, C. Boudinet, and J. L. Schanen, "Evaluation of loss effect on optimum operation of variable speed micro-hydropower energy conversion systems," Renewable energy, vol. 131, pp. 1022-1034, 2019.

[4] S. Doolla, and T. S. Bhatti. "Load frequency control of an isolated small-hydro power plant with reduced dump load." IEEE Transactions on Power Systems 21, no. 4 (2006): 1912-1919.

[5] S. Doolla, T. S. Bhatti, and R. C. Bansal. "Load frequency control of an isolated small hydro power plant using multi-pipe scheme." Electric Power Components and Systems 39, no. 1 (2011): 46-63.

[6] M. Hanmandlu and H. Goyal, "Proposing a new advanced control technique for micro hydro power plants," International Journal of Electrical Power $\backslash \&$ Energy Systems, vol. 30, pp. 272-282, 2008.

[7] L. Belhadji, S. Bacha, and D. Roye, "Modeling and control of variable-speed micro-hydropower plant based on axial-flow turbine and permanent magnet synchronous generator (MHPP-PMSG)," in IECON 2011-37th Annual Conference of the IEEE Industrial Electronics Society, 2011, pp. 896-901.

[8] M. Hanmandlu and H. Goyal, "Proposing a new advanced control technique for micro hydro power plants." International Journal of Electrical Power $\backslash \&$ Energy Systems 30, no. 4 (2008): 272-282.

[9] R. R. Singh, B. A. Kumar, D. Shruthi, R. Panda, and C. T. Raj. "Review and experimental illustrations of electronic load controller used in standalone MicroHydro generating plants." Engineering science and technology, an international journal 21, no. 5 (2018): 886-900.

[10] B. Singh, S. S. Murthy, and S. Gupta. "Transient analysis of self-excited induction generator with electronic load controller (ELC) supplying static and dynamic loads." IEEE Transactions on Industry Applications 41, no. 5 (2005): 1194-1204.

[11] K. Shahzad, A. R. Khan, M. S. Khalid, and A. Qamar. "Voltage and Frequency Control of PV, Micro-hydro and Biomass Based Islanded Microgrid." In 2018 Clemson University Power Systems Conference (PSC), pp. 1-6. IEEE, 2018.

[12] A. Uniyal and S. Sarangi, "Optimal allocation of ELC in microgrid using droop-controlled load flow," IET Generation, Transmission $\backslash \&$ Distribution, vol. 13, pp. 4566-4578, 2019.

[13] U. K. Kalla, B. Singh, and S. S. Murthy. "Modified electronic load controller for constant frequency operation with voltage regulation of small hydro-driven single-phase SEIG." IEEE Transactions on Industry Applications 52, no. 4 (2016): 2789-2800.

[14] B. N. Roodsari, E. P. Nowicki, and P. Freere. "The distributed electronic load controller: a new concept for 
voltage regulation in microhydro systems with transfer of excess power to households." Energy Procedia 57 (2014): 1465-1474.

[15] R. A. Ofosu, K. K. Kaberere, J. N. Nderu, and S. I. Kamau. "Design of BFA-optimized fuzzy electronic load controller for micro hydro power plants." Energy for Sustainable Development 51 (2019): 13-20.

[16] B. Singh, S. S. Murthy, R. R. Chilipi, S. Madishetti, and G. Bhuvaneswari. "Static synchronous compensatorvariable frequency drive for voltage and frequency control of small-hydro driven self-excited induction generators system." IET Generation, Transmission $1 \&$ Distribution 8, no. 9 (2014): 1528-1538.

[17] R. R. Chilipi, B. Singh, and S. S. Murthy. "Performance of a self-excited induction generator with DSTATCOMDTC drive-based voltage and frequency controller." IEEE Transactions on energy conversion 29, no. 3 (2014): 545-557.

[18] Y. Xu, C. Li, Z. Wang, N. Zhang, and B. Peng. "Load frequency control of a novel renewable energy integrated micro-grid containing pumped hydropower energy storage." IEEE Access 6 (2018): 29067-29077.

[19] D. A. Pedroso, C. A. de Souza, L. G. Scherer, and R F. de Camargo. "Development and Control of a Hydro-PV Power Generation System with BESS and ELC." In 2019 IEEE PES Innovative Smart Grid Technologies Conference-Latin America (ISGT Latin America), pp. 16. IEEE, 2019. 